\title{
Effects of Wireless Devices on Human Body
}

\section{Larik RSA ${ }^{1 *}$, Mallah GA ${ }^{1}$, Talpur MMA ${ }^{1}$, Suhag $\mathrm{AK}^{2}$ and Larik $\mathrm{FA}^{3}$}

${ }^{1}$ Department of Computer Science, Shah Abdul Latif University, Khairpur Mir's, Sindh, Pakistan

${ }^{2}$ Department of Chemistry, Quaid-i-Azam University, Islamabad 45320, Pakistan

${ }^{3}$ Department of Education, Sindh Madressatul Islam University, Karachi, Pakistan

\begin{abstract}
The wireless devices have become the integral part of our everyday life. These devices are being used for many purposes such as for Internet and Telecommunication. Being a theoretical approach, the purpose of this study is to investigate the effects of wireless devices on human body. These devices emit the harmful radiations which cause the diseases like male infertility, brain tumor, hearing impairment, fetus, effect on eyes, etc. Besides, these radiations severely affect other various parts of human body. This study investigated three major diseases, i.e., brain tumor, male infertility and hearing impairment. The survey/investigations have been conducted from number of medical practitioners working in various hospitals and medical centers of District Sukkur and Khairpur Mirs'. The results, collected through interviews and survey, show the intensity of harm of different wireless devices; Mobile phone is the most effective device with $96 \%$, Bluetooth Device $32 \%$, Laptop $54 \%$, Tablet PC $14 \%$ and Wireless router $20 \%$.
\end{abstract}

Keywords: Wireless devices; Human body; Diseases; DNA damage

\section{Introduction}

The Wireless technology was devised in 1880 by Alexander Graham Bell and Sumner Tainted when the photo phone invented [1]. Nowadays, there are many types of wireless devices being used to communicate. Mobile phone and Wireless Network are the part of our daily life throughout the world. The Wi-Fi device allows the exchange (receiving and sending) data through wirelessly and Wi-Fi devices emit radio waves. Devices that use Wi-Fi are tablet pc, cell phone, audio player, PC and digital camera. The wireless devices are based IEEE standard $802.11[2]$

Nowadays, the using of wireless devices increased day by day because these devices do not use the physical cable that is for the purpose of communication. These devices use the electromagnetic radiation for receive and send the data through the air, either it is sound data or network data. These devices emit harmful radiations are affected on human body because such radiations are present everywhere that we cannot neither feel nor see. These radiations penetrate in our body and effect on the cell's DNA (The DNA is genetic material of cell that is sensitive to ionizing radiation. With the ionizing radiation the DNA of cell can be changed [3]).

The several types of radiation are being used for connecting the wireless devices and each type of radiation has different wavelength and frequency, the frequency of radiation is from $3 \mathrm{kHz}$ to $300 \mathrm{GHz}$. There are different wireless devices which are hand free, wireless router, tablet pc, Cell phone tower, Mobile phone, Bluetooth device, laptop connected with the wireless router and audio player. These wireless devices emit the harmful radiations, which cause of many diseases i.e., Male Infertility, miscarriage risk, Brain Tumor, Ear Hearing Impairment, effect on fetus, increasing risk of cancer, Parkinson's disease, Alzheimer's disease [4], Heart disease, asthma, insomnia, leukemia, high blood pressure, birth defects, rheumatoid arthritis, Immune system. Radiations are also cause of some symptoms which are fatigue, sleep disturbance, headache etc.

This is survey based research and survey is conducted from the medical doctors with the help of survey questionnaire; this survey contains the 3 diseases which are male infertility, Ear hearing impairment and Brain Tumor.

\section{Radiation}

Radiation is energy that originates from the unstable atom, and the radiation is the form of wave particles, radiations transfer or spread in the form of particle or wave or rays through the space. There are two types of radiations which are ionizing and non-ionizing radiation. The non-ionizing radiations are directly transmit (sending and receiving) of electromagnetic radiation or sound energy or heat energy and it does not break the chemical bond [5] but the ionizing radiation is composition of high energy waves that can easily remove or move the electrons from the molecules, atoms and cause the cell damage also increase the risk of many diseases [6]. According to the medical test the low amount of ionizing radiation is not much harmful, but the high amount of ionization of radiation can radiation sickness, cause cancer etc. The DNA is genetic material of cell that is sensitive to ionize radiation. With the ionizing radiation the DNA of cell can be changed [7].

The electromagnetic radiation is divided into other different types of radiation. The radio wavelength is from $0.5 \mathrm{~cm}$ to $30,000 \mathrm{~m}$ [8]. Microwave radiation is electromagnetic radiation its frequency is from $0.3 \mathrm{GHz}$ to $300 \mathrm{GHz}$. The frequency range relates to the wavelengths between one millimeter and one meter [9]. The Infrared radiations are in between microwaves and visible light. The Infrared is classified in three categories "near" infrared, "mid" infrared and "far" infrared. The visible light is in between the infrared and ultraviolet in the electromagnetic spectrum. It is the smallest part of electromagnetic spectrum that spread from the cosmic rays. The wavelength of visible light is visible to the human eyes. The frequency of visible light is $4 \times$ $10^{14}$ to $8 \times 10^{14}$ cycles/sec or $\mathrm{Hz}$ and the wavelength is about $740 \mathrm{~nm}$ (nanometers) to $380 \mathrm{~nm}$. The wavelength of ultraviolet light is shorter than visible light, so this type of waves are not visible to human eyes

*Corresponding author: Raja Sohail Ahmed Larik, Shah Abdul Latif University Khairpur Mir's, Sindh, Pakistan, Tel: +923005888648; E-mail: r.sadraei1989@gmail.com

Received May 28, 2016; Accepted June 21, 2016; Published June 27, 2016

Citation: Larik RSA, Mallah GA, Talpur MMA, Suhag AK, Larik FA (2016) Effects of Wireless Devices on Human Body. J Comput Sci Syst Biol 9: 119-124. doi:10.4172 jcsb. 1000229

Copyright: @ 2016 Larik RSA, et al. This is an open-access article distributed under the terms of the Creative Commons Attribution License, which permits unrestricted use, distribution, and reproduction in any medium, provided the original author and source are credited. 
but the some insects can see these waves, as the bumblebees can see these waves. The frequency range of ultraviolet light is from $8 \times 10^{14}$ to $3 \times 10^{16}$ Hertz. The $\mathrm{X}$-rays are ionizing radiation that has enough energy to eject the electron from the atom or molecule and also change the chromosomes, gene and some other components of cell [10]. The frequency of gamma waves is high, the wavelength of gamma rays are very small but have more packets of energy, that energy is known as the photons without any charge. The gamma rays are generating during breakdown of atomic nuclei. The wavelength of gamma rays is $100 \mathrm{pm}$ (pico-meters) it is shorter; the frequency of gamma rays is more than $10 \mathrm{EHz}[11]$

\section{Disease Introduction}

\section{Male infertility}

The reproduction is natural experience for couples. However, it is very difficult to plan for the baby. Basically the infertility is wide problem in the world due to different reasons. The male infertility problem creates due to the sperm production (sperm production in low number) or the transport process of sperm [12]. The infertility problems are sperm motility, sperm count, sperm morphology, functions of sperm, impaired leydig cell, sertoli cell, abnormality of sperms, to stop delivery of sperm, chronic wellness problem [13].

\section{Brain tumor}

It is a mass of tissue that is abnormal or you can say that the body cells die or replaced with other cells and other tumors [14]. There are two types of Brain Tumor which are malignant tumor and benign tumor cause the electromagnetic radiation [15].

\section{Ear impairment}

Hearing problem usually develops according to the age and loud noise. There are different causes of hearing loss that are creates difficulty in hearing means the people cannot listen clearly and asking people again and again. The cause of hearing loss is listening to music with high volume [16].

\section{Literature Review}

\section{Male infertility}

Nowadays, a cell phone is being kept very close to groin area by human, like near the testis such as trouser pocket is commonly used for carrying mobile phone [17]. Electromagnetic waves have a harmful effect on male sex organs and sperm. These radiations can cause changes in shapes, motility and number of sperms. Radiations from cell phone can harms to the structure and function of testis and decrease of male fertility. The major organs which came under the damage due to cell phone radiations are leydig cells, and seminiferous tubules. Testosterone biogenesis is affected and DNA sperm damage occurs by radiations due to the cell phone [18]. The radiofrequency radiation of Wi-Fi $2.4 \mathrm{GHz}$ has harmful effects on semen. The use of Wi-Fi devices has close contact with our body [19]. Exposure of human sperms to Wi-Fi internet connected with laptop causes decrease the motility and increase the DNA fragmentation due to the non-thermal effect. These types of technologies must be used carefully by pregnant women while it is plugged-in, [20] when male is exposed the effects of environment is cause of decrease of the capabilities of male infertility. These are the hazardous effects on the sperm parameters (structure and mobility) [21]. A significant decrease in the motile sperms was found by Wdowiak. Total $65.7 \%$ of patients who were not using cell phones that are showed normal sperm motility but $17 \%$ of patients showed abnormal sperm motility who was cell phone users [22].

\section{Brain tumor}

The frequency range from $40 \mathrm{MHz}$ to $6 \mathrm{GHz}$ deeply penetrates inside tissues because irregular molecular motion, this effects on DNA. The RF-EMR from the wireless device directly produces changes in DNA shape. The electromagnetic field exposure may elevate the occurrence of cancer and brain tumor. During the use of cell phone near the ear/brain can penetrate inside human brain as deep as 4 to 6 $\mathrm{cm}$. due to this actions of radiations the hippocampus and pineal gland affected by decreasing in their protein kinase $\mathrm{C}$ and melatonin activity. The tumor formation occurs because cell phone is being used in a very close contact with the brain, if cell phone will be used one hour per day continuously exposure about 10 years or above will increase risk of brain tumor. Long term use of cell phone develop brain tumor and microwave frequencies produce changes in brain DNA and micronuclei [23]. The microwave frequencies are more effective to the brains of children than the adult because bodies of young peoples are still under development their cells are dividing more; they have a thin skull and brain [24]. The radiation of cell phone increases the brain tumor, because the blood brain barrier damage due to these radiations. The cells of brain relates with memory of learning. The calcium releases from the cell membrane by weak electromagnetic fields [25].

\section{Ear impairment}

The effect of electromagnetic waves can on the hearing damage due to the long term use of cell phone. The cause of hearing loss took place when the user uses long time cell phone with the higher frequency. Almost many users use the right ear for listen the call as compared to the left ear [26]. The cell phone radiation damage the inner ear and the long term use of cell phone for four year or more averagely 30 minute per day use of cell phone is harmful for the hearing function, which activates the cochlear receptor through the same process which involved in the normal hearing, that describes the "clicks" which are heard by the people that exposed to the microwave radiation. Most of the young peoples between the age of 18 to 25 suffering from the loss hearing function due to more use of cell phone and other gadgets, doctors say. There are 16000 hair cells which are present in each of inner ear. When cells are not regenerating then hearing problems took place. Peoples who are using their cell phone every day from 2 to 3 hours are at the partial deafness risk during 3 to 5 years. Most of the peoples during the age of 20 s working in marketing and teleconsulting professionals are using cell phone initially feeling ear pain then slowly tinnitus develops [27]. The use of cell phone has been increased so, the possibility of biological effects due to the cell phone emit radiofrequency that consists on magnetic fields and oscillating electric which interact negatively with the cells of plants, human beings and animals. The radiofrequency electromagnetic radiations are being used for the wireless communication devices is more effective for the human health, like blood pressure, short term memory loss, brain tumor, sleep disturbances. The radiofrequency is focused in tissue close to the mobile that includes auditory nerve. During the use of mobile phone, the inner ear and around ear skin absorb the microwave energy and radiofrequency which cause of hearing impairment [28].

\section{Survey and Methodology}

This study is based on the theoretical approach and survey for collecting the results from the several medical doctors. The secondary data collected through the journal, textbooks and article. The survey 
questionnaire was interviewed for data collection from the medical doctors and other para medical staff. The survey was conducted at City Hospital Khairpur, Civil Hospital Khairpur, Ghulam Mohammad Mahar Medical College Sukkur and different medical centers.

A questionnaire was designed for conducting interview. It contained fifteen questions which cover sufficient information about wireless devices that affect human health and raise different diseases. The other questions were related to the number of people affected by the wireless radiation observed by doctors. There were 300 questionnaires which were distributed in medical doctors of different diseases in different hospitals and medical center for collecting the survey results. In result, each doctor has given his own ideas about the effects of wireless devices on human body based on their observations about the patients.

\section{Data collection}

Data collection was started from several hospitals of Khairpur and Sukkur. Initially, we visited Civil Hospital Khairpur where civil surgeon of hospital was requested to allow and co-operate in completing the task of survey while suggesting doctors. The questionnaires distributed to all doctors and they also were interviewed for data collection about the effects of wireless devices on human body and got their recommendations as well.

Then we visited city Hospital and other private medical centers for this purpose, like Khairpur civil hospitals, GMMMC of district. We also visited Sukkur to ascertain the factual information of wireless radiation and its impact on human body. Same procedure of data collection was applied there.

\section{Results}

A total of 300 Medical Doctors were surveyed about the effect of wireless devices on human body. On the basis of patients under their treatment, $99 \%$ medical doctors gave a positive response to the effect of wireless devices on human body and $1 \%$ medical doctors gave a negative response to the effects of wireless devices on human body. The results are shown in the following Figure 1.

The more affecting wireless devices were included Mobile 96\%,
Laptop 54\%, Tablet PC 14\%, Wireless Router 20\% and Bluetooth Device $32 \%$. According to medical doctors the more affecting wireless devices are shown in the Figure 2 (in percentage).

According to our survey of Medical Doctor's the cause of diseases is using of wireless devices like Brain Tumor $84 \%$, Male Infertility $36 \%$, Heart Disease 46\%, Effect on Fetus 20\%, Ear Hearing Function 82\%, Alzheimer's Disease 10\% and Parkinson's Disease 2\%. These results are shown in the following Figure 3.

Figure of Brain Tumor, male infertility and ear caused by different devices (shown in Figure 4) which are Mobile 76\%, 36\% and $92 \%$ respectively, Laptop $8 \%, 68 \%$ and $0 \%$, Tablet PC $2 \%, 4 \%$ and $0 \%$, Bluetooth device $2 \%, 0 \%$ and $6 \%$, Wireless router $10 \%, 2 \%$ and $0 \%$, Wireless headphone $30 \%, 0 \%$ and $52 \%$, Wi-Fi $4 \%, 2 \%$ and $0 \%$ and Cell phone tower $4 \%, 2 \%$ and $0 \%$.

\section{Discussion}

Comparatively area under the study has not been explored for the investigation of the potential of the effects of radiations emitted by wireless devices. With slight variation present study confirms the harmful effects of the radiation on body of the people of area selected for the study as revealed by medical doctors. Purposefully, correct study aimed to create awareness among the people in journal and the people living in the area under the study, to avoid the use of such devices, which is involved in the onset of debilitating diseases mentioned in our study.

In this way our research has revealed that the prolonged use of such devices are at risk greater risk as the harmful effects may cause permanent damages which may not be repaired. The survey obtained from the doctors revealed that there is harmful effect of cell phone, laptop, tablet pc wireless router and blue tooth device on human body because these devices emit the different types of radiations. These radiations penetrate in our body and damage the DNA [29]. The doctors have given the $99 \%$ positive response in favor of harmful effects because they were treating that type of patients.

The use of wireless devices increase nowadays and their strength of radiation is mobile phone $(1800 \mathrm{MHz}$ and $3 \mathrm{G}$ technology operate between $1900 \mathrm{MHz}-2200 \mathrm{MHz}$ ), laptop (1000 MHz-3600 MHz), Wi-Fi

\section{Can Wireless Radiation Effect on Human Body}

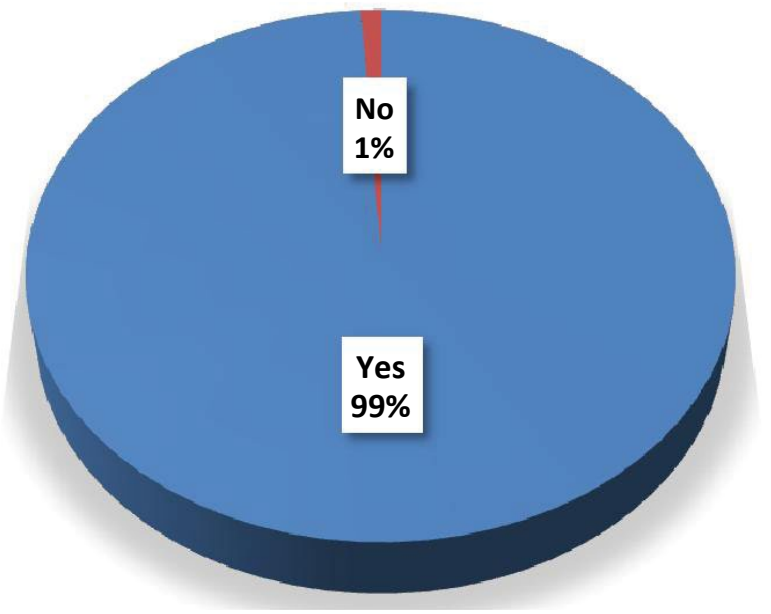




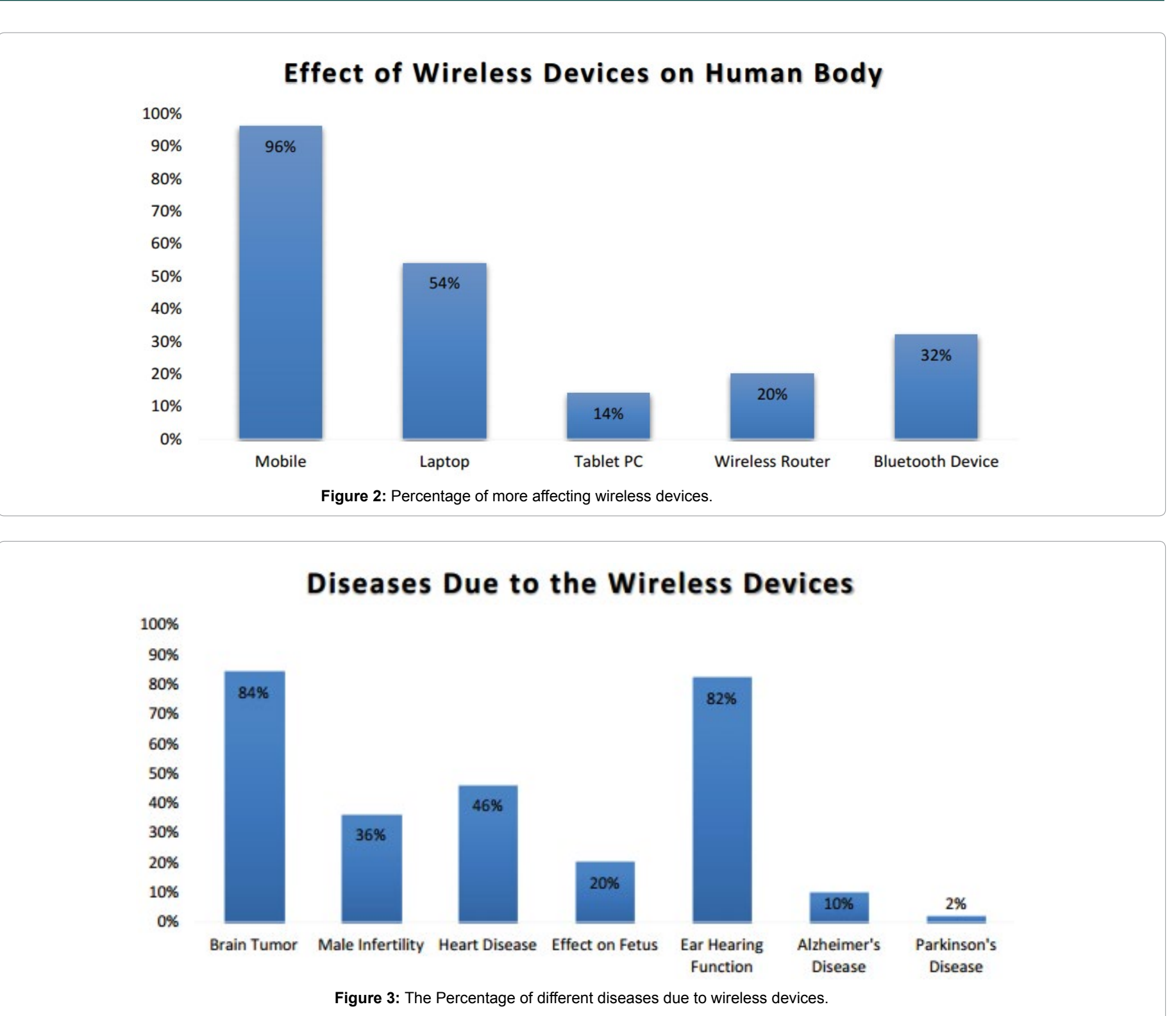

(2450 MHz) [30], Tablet PC (2.4 GHz) and Bluetooth devices $(2.4 \mathrm{GHz})$ [31], as cell phone has becomes a part of our life, but cell phone emit harmful radiation that are effected on our health. The present study is in agreement with Khudnitskii et al. [32] who found that high frequency radiation has an influence on the function of central nervous system (CNS) because of phone antenna proximity to the area of head that gets severe heating. Kellenyi et al. [33] discovered that deficiency in the hearing system was caused by the exposure of mobile phone radiation; this is in conformity with our study. According to the Meo et al. [34] about $34.59 \%$ of problems were correlated with impaired hearing, ear warmth and ache on ear, $23.07 \%$ effect on ear were found, $23 \%$ hearing problem found due to the cell phone $[35,36]$ and in our study we found $82 \%$ effect on ear, that is not in agreement with current study. Meo et al. found $5.04 \%$ of problem with the decreased and blurred vision due to the mobile phone; in our survey research we found $62 \%$ effect on eyes during using cell phone. According to Vasudev et al. [37] constant use of cell phones can lead $44.4 \%$ decrease in fertility level, $30 \%$ sperm damage was found by the Hungarian Scientists [38] and in present study the effect was $36 \%$. The effect to the heart's function was $50.0 \%$ according to Vasudev et al. [39] and in current study the effects was $46 \%$ that is an agreement with current study. $32.3 \%$ effects on brain tumor was found by Al-Muhayawi et al. [40], according to the world health organization report the cell phone radiation has $40 \%$ effect on brain tumor [41] and according to our study the effect on brain tumor was 84\%. Johansson found the effect of cell phone on Alzheimer's disease [42]. The diseases due to the electromagnetic field are immune system damage, Alzheimer's disease, Parkinson's disease and heart problems [43]. Divan et al. found the effect of cell phone radiation on prenatal and postnatal, it was examined that the effect on unborn baby when mother use the cell phone and laptop (when laptop connected with Wi$\mathrm{Fi}$ ), these radiations are bad for unborn baby's brain development and also cell phone radiation effects our brain [44].

\section{Conclusion}

It is concluded that the use of wireless devices have been increased throughout the world, these devices become the part of our life, but 


\section{Brain Tumor, Male Infertility \& Ear caused by Wireless Devices}

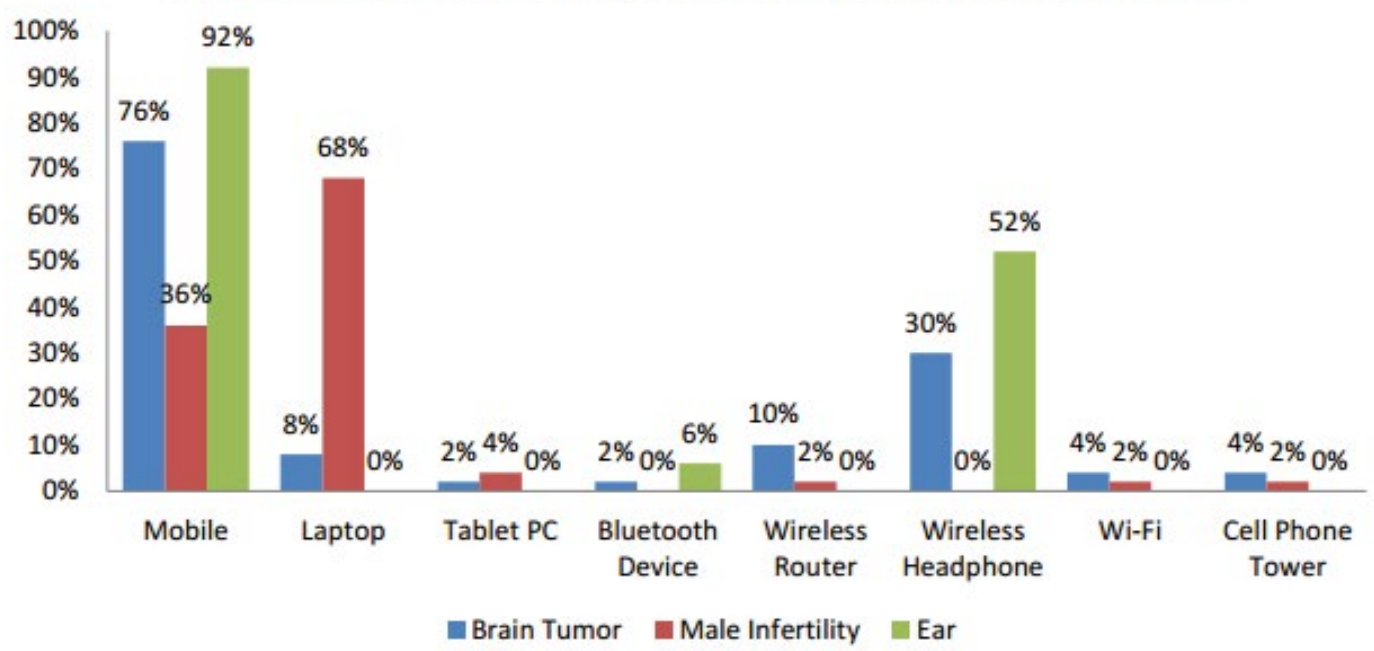

Figure 4: Percentage of Brain tumor, Male infertility and Ear caused by wireless devices.

many peoples are unaware about the effects on human health on the using of devices. All wireless devices emit radiation in the form of electromagnetic field. The current study was focused on three diseases which are male infertility, Brain tumor, and ear impairment. According to our survey from the City Hospital Khairpur Mir's, Civil Hospital Khairpur Mir's, Ghulam Muhammad Mahar Medical College Sukkur and other medical centers, we observed that the mobile phone is more dangerous for our health, as doctors believed that wireless devices such as cell phones, laptop, wireless router, wireless headphone, cell phone tower, Bluetooth devices and tablet pc is cause of the disease of brain tumor, male infertility, heart disease, effect on fetus, hearing impairment, eye problems, immune system, leukemia, Alzheimer's disease and Parkinson's disease. It is suggested that one should avoid the use of wireless devices or to minimize the timing as possible to save the human health.

\section{Recommendations}

- According to our survey the wireless devices emit radiations are harmful to human health so there are some recommendations that one should use one's cell phone when it is necessary.

- Don't put the cell phone in a pant and shirt pocket.

- Don't use the cell phone for long-term which is harmful to health because doctors suggesting the use of cell phone for 1 hour in a day which cause of brain tumor within 10 years.

- Avoid the long time conversation, use head phone when you have to talk for long call.

- Avoid using the wireless gadget like cell phone, laptop, tablet pc, wireless keyboard and mouse so on.

- Don't place the laptop on a lap when it is connected to Wi-Fi because it is harmful for sperms and also effect on the fetus, specially pregnant women avoid to use tablet, PC, laptop and cell phone.

- Don't use wireless devices in schools and colleges because it is harmful for the children and it is suggested that use the land line phone and DSL.
- Each and every one should know about the effects of these wireless radiations on human body, in this regard public awareness programs may be designed and executed as soon as possible by the concerned authorities.

- Government should take an action on cell phone towers existing in or near populated areas because cell phone towers emit the harmful radio waves which are a cause of human health problems.

- The installation of towers in the populated area may be banned and if they are already installed, should be removed immediately to save the people from their dangerous effects of radiations.

\section{References}

1. Carson MK (2007) Alexander Graham Bell: Giving voice to the world. Sterling Publishing Company Inc., New York, USA.

2. Collins L, Ellis SR (2015) Mobile Devices: Tools and Technologies. CRC Press, USA.

3. Setubal JC, Meidanis J (1997) Introduction to computational molecular biology PWS Publishing Company, Boston, USA.

4. Sage C, Carpenter DO (2009) Public health implications of wireless technologies. Pathophysiology 16: 233-246.

5. Author not listed (2012) Radiation: Facts, Risks and Realities. United States Environmental Protection Agency EPA-402-K-10-008.

6. Carpenter DO (2013) Human disease resulting from exposure to electromagnetic fields. Rev Environ Health 28: 159-172.

7. Boyce JD Jr. (2015) lonizing Radiation and Breast Cancer Risk Fact Sheet \#52. International Epidemiology Institute, Rockville, MD 20850.

8. http://science.nasa.gov/missions/

9. Townes CH, Schawlow AL (2013) Microwave spectroscopy. Courier Corporation, USA.

10. Agarwal BK (1991) X-ray spectroscopy: an introduction. Volume 15. SpringerVerlag, Berlin Heidelberg, Germany.

11. May L (2012) An introduction to Mössbauer spectroscopy. Springer Science \& Business Media, Germany.

12. Dohle GR (2010) Male infertility in cancer patients: review of the literature. Int J Urol 17: 327-331. 
Citation: Larik RSA, Mallah GA, Talpur MMA, Suhag AK, Larik FA (2016) Effects of Wireless Devices on Human Body. J Comput Sci Syst Biol 9: 119-124. doi:10.4172/jcsb.1000229

13. Hamada AJ, Singh A, Agarwal A (2011) Cell phones and their impact on male fertility: fact or fiction. The Op Repro Sci J 5: 125-137.

14. Kircher M, de la Zerda A, Jokerst JV, Zavaleta CL, Kempen PJ, et al. (2012) A brain tumor molecular imaging strategy using a new triple-modality MRIphotoacoustic-Raman nanoparticle. Nat Med 18: 829-834.

15. Janic A, Mendizabal L, Llamazares S, Rossell D, Gonzalez C (2010) Ectopic expression of germline genes drives malignant brain tumor growth in Drosophila. Science 330: 1824-1827.

16. Rana RK, Chou CT, Kanhere SS, Bulusu N, Hu W (2010) Ear-phone: an end-toend participatory urban noise mapping system. In Proceedings of the $9^{\text {th }} \mathrm{ACM} /$ IEEE International Conference on Information Processing in Sensor Networks, Stockholm, Sweden. pp: 105-116.

17. Kibona L (2013) Assessment of The Impact of Electromagnetic Radiations From Mobile Phone Towers On Male Sperm Infertility. Int J Tech Enhance Emer Eng Res 1: 80-85.

18. Khullar S (2012) Impact of Electromagnetic Waves Generated by Cellular Phones on Male Fertility: A Review. Asi J Biomedi Pharmaceu Sci 2: 9-14.

19. Oni OM, Amuda DB, Gilbert CE (2011) Effects of radiofrequency radiation from Wi-Fi devices on human ejaculated semen. Int J Res Rev Appl Sci 9: 292-294.

20. Bhavanarayana B, Basha SK, Manohar P (2014) Effects of electromagnetic waves on male reproduction. Int J Pharma Life Sci 5: 3917-3926.

21. Wdowiak A, Wdowiak L, Wiktor H (2007) Evaluation of the effect of using mobile phones on male fertility. Ann Agric Environ Med 14: 169-172.

22. Agarwal A, Desai NR, Makker K, Varghese A, Mouradi R, et al. (2009) Effect of radiofrequency electromagnetic waves (RF-EMW) from cellular phones on human ejaculated semen: an in vitro pilot study. Fertil Steril 92:1318-1325.

23. Starkey S (2011) Discussing mobile phone safety with young people. Brit J Sch Nurs 6: 434-438.

24. Emami Z, Turan AG, Razavi GSE (2012) Study on the relationship between electromagnetic waves of cell phone and the prevalence of the Glioma and Meningioma.

25. Simko M (2007) Cell type specific redox status is responsible for diverse electromagnetic field effects. Curr Med Chem 14: 1141-1152.

26. Bhatia MS, Sharma V, Chhabra V (2008) Neuropsychiatric Effects of Mobile Phones. Del Psych J 11: 52-58.

27. Al-Bareeq JM (1998) Health Risks of Electromagnetic Field. J Bahr Med Bull 20: $1-2$.

28. Al-Abduljawad KA (2011) Effects of the mobile phones on the hearing function of users. J Bahr Med Bull 30: 72-74.

29. Keller A, Rackwitz J, Cauët E, Liévin J, Körzdörfer T, et al. (2014) Sequence dependence of electron-induced DNA strand breakage revealed by DNA nanoarrays. Scient rep, p: 4.

30. Pirogova E, Cosic I, Vojisavljevic V (2009) Biological effects of electromagnetic radiation. INTECH open Access Publisher, Croatia.

31. Nishiyama H, Ito $\mathrm{M}$, Kato N (2014) Relay-by-smartphone: realizing multihop device-to-device communications. IEEE Com Mag 52: 56-65.

32. Khudnitskiĭ SS, Moshkarev EA, Fomenko TV (1999) On the evaluation of the influence of cellular phones on their users. Med Tr Prom Ekol 9: 20-24.

33. Kellenyi L, Thuroczy GY, Faludy B, Lenard L (1999) Effects of mobile GSM radiotelephone exposure on the auditory brainstem response (ABR). Neurobiology (Bp) 7: 79-81.

34. Meo SA, Al-Dreess AM (2005) Mobile phone related hazards and subjective hearing and vision symptoms in the Saudi population. Int J Occup Med Environ Health 18: 45-49.

35. Braune S, Wrocklage C, Raczek J, Gailus T, Lücking CH (1998) Resting blood pressure increase during exposure to a radio-frequency electromagnetic field. The Lancet 351: 1857-1858.

36. Szyjkowska A, Gadzicka E, Szymczak W, Bortkiewicz A (2014) The risk of subjective symptoms in mobile phone users in Poland-an epidemiological study. Int J Occup Med Environ Health 27: 293-303.

37. Vasudev A, Kaur M, Kumar H, Chaturvedi R (2012) Mobile Phone Usage and Awareness of Health Related Issues Among the Male Science Students. Stud Sociol Sci 3: 62-67.

38. http://www.powerwatch.org.uk/reports/20041222_reflex.pdf

39. Al-Muhayawi S, Eldeek B, Abubakr H, BenKuddah R, Zahid A, et al. (2012) The Impact of Medical Students' Awareness of Cell Phone Use and its Health, Life Sci J 9: 1143-1148.

40. Gaudin N (2011) WHO/IARC Classifies Radiofrequency Electromagnetic Fields as Possible Carcinogenic to Humans, World Health Organization.

41. https://mobilephonetruth.wordpress.com/2012/03/26/mobile-phones-causing alzhimer/ (Accessed on June 22, 2016)

42. Divan HA, Kheifets L, Obel C, Olsen J (2008) Prenatal and postnatal exposure to cell phone use and behavioral problems in children. Epidemiology 19 523-529.

43. Hillman D (2014) Effects of Extraneous Electricity on Dairy Cattle, Other Animals, and Humans-A Guide for Dairymen, Veterinarians, and Investigators of Stray Voltage. J Vet Sci Med Diagn, p: 3.

44. Uddin AS, Ferdous J (2010) Radiation exposure of cell phones \& its impact on human health-a case study in South Asia (Bangladesh) and some recommendations. J Theoret Appli Info Tech 19: 15-21. 